\title{
Development and Feasibility of a Patient-Derived Training Simulator for Image-Guided Adaptive Brachytherapy of Locally Advanced Cervical Cancers
}

\section{Kento Tomizawa}

Gunma University: Gunma Daigaku

Takahiro Oike ( $D$ oiketakahiro@gunma-u.ac.jp)

Gunma University Heavy Ion Medical Center https://orcid.org/0000-0003-1332-4306

Ken Ando

Gunma University: Gunma Daigaku

Daisuke Irie

Gunma University: Gunma Daigaku

Makoto Sakai

Gunma University: Gunma Daigaku

Hirofumi Shimada

Gunma University: Gunma Daigaku

Tatsuya Ohno

Gunma University: Gunma Daigaku

\section{Research}

Keywords: cervical cancer, image-guided adaptive brachytherapy, interstitial needles, training, 3D modeling, IC/IS applicator

Posted Date: December 17th, 2021

DOI: https://doi.org/10.21203/rs.3.rs-1160843/v1

License: (9) This work is licensed under a Creative Commons Attribution 4.0 International License. Read Full License 


\section{Abstract \\ Background}

Image-guided adaptive brachytherapy (IGABT) plays a pivotal role in definitive radiotherapy of cervical cancer. Although the combination of a tandem and ovoid applicator with interstitial needles (IC/IS brachytherapy) is an efficient IGABT technique for bulky irregular-shaped tumors, training opportunities for IC/IS brachytherapy remain limited. Thus, we developed a training simulator for IC/IS brachytherapy for locally advanced cervical cancer and tested its feasibility.

\section{Methods}

The training simulator combined a patient-derived soft silicone tumor phantom with an acrylic tube mimicking the vagina. The tumor phantom was modeled on a cervical cancer patient treated with IGABT at our institute between 2012-2020, through detailed inspection of their three-dimensional (3D) high-risk clinical target volume (HR-CTV) at the first brachytherapy session. A true-scale tumor phantom was created from the HR-CTV data using 3D-printing. The feasibility of the training simulator was investigated by comparing treatment plans between the following six sessions (sessions \#1-\#3, with a Fletcher-Suit Asian Pacific applicator; \#4-\#6, with a Venezia applicator): in sessions \#1 and \#4, an expert inserted a tandem and ovoids (T\&O); in sessions \#2 and \#5, a resident inserted a T\&O plus four needles; and in sessions \#3 and \#6, an expert inserted a T\&O plus four needles. At each session, the highest possible dose was prescribed to the HR-CTV while keeping the $D_{2 c c}$ of the rectum and bladder (derived from the model case) below 6 and $7.6 \mathrm{~Gy}$, respectively.

\section{Results}

The training simulator was developed using the HR-CTV data of a FIGO stage IIIB tumor $(68 \cdot 49 \cdot 45 \mathrm{~mm})$ selected from one of 495 candidates. The feasibility tests with a Fletcher-Suit Asian Pacific applicator resulted in HR-CTV $D_{90}$ of $4.23,5.69$, and 6.70 Gy for sessions \#1, \#2, and \#3, respectively. With a Venezia applicator, HR-CTV $D_{90}$ was $4.16,6.20$, and 6.45 Gy for sessions \#4, \#5, and \#6, respectively.

\section{Conclusions}

The tumor phantom was a good representation that resulted in various HR-CTV $D_{90}$ doses depending on the physician's experience and applicator type. Further evaluation of the training simulator is warranted to confirm its educational value for IC/IS brachytherapy for locally advanced cervical cancer.

\section{Background}


Cervical cancer causes more than 300000 deaths worldwide annually, and its mortality ranks fourth among all cancers [1]. Radiotherapy plays a pivotal role in the definitive treatment of locally advanced cervical cancers [2], with definitive radiotherapy approaches including external beam radiotherapy (EBRT) and brachytherapy [3]. For the latter, image-guided adaptive brachytherapy (IGABT) using magnetic resonance imaging (MRI) or computed tomography (CT) has become widespread in recent years $[4,5]$. The introduction of IGABT technologies into definitive radiotherapy practice has dramatically improved the oncologic outcomes of cervical cancers $[6,7]$.

Despite the technological advancements, IGABT using a tandem and ovoid applicator alone results in suboptimal dose coverage for bulky or irregular-shaped tumors, leading to insufficient tumor control [8,9]. To deliver a sufficient dose to such tumors, the tandem and ovoid applicator can be supplemented with a few interstitial needles. In 2011, our group introduced a combination of a few interstitial needles with a Fletcher-Suit Asian Pacific applicator (Elekta, Stockholm, Sweden) under in-room CT guidance [10]. Multiple studies have shown that this combined intracavitary and interstitial (IC/IS) brachytherapy has excellent outcomes for locally advanced disease $[7,11]$. Additionally, brachytherapy applicators equipped with a template for needle insertion have been developed by several groups. In 2006, Dimopoulos et al. introduced the Vienna applicator consisting of a tandem and a ring that enables needle insertion from predefined directions guided through the holes in the ring [12]. In 2009, Jürgenliemk-Schulz et al. introduced the Utrecht applicator consisting of a tandem and two oval ovoids that enables needle insertion from more-varied directions than the Vienna applicator, with the needles guided through the holes in the ovoids [13]. In 2018, Walter et al. introduced the Venezia applicator consisting of a tandem and two lunar-shaped ovoids (that form a ring in combination) functioning as a needle template [14].

The key to the success of IC/IS brachytherapy is to insert the interstitial needles in locations appropriate to achieving a highly conformal dose to the targeted tumor volume. However, the training opportunities for needle application are limited, thereby preventing this technique from becoming widely used by radiation oncologists. To address this issue, this study aimed to develop a training simulator for IC/IS brachytherapy for locally advanced cervical cancer, and to report on its feasibility with different applicator types and physicians with different levels of experience of IGABT.

\section{Methods}

\section{Foundation of the simulator}

First, the foundation of the simulator was developed using transparent acryl to provide visibility; no metal was used to ensure that the simulator was CT and MRI compatible. To enable a physician to approach through the vagina, an acrylic tube mimicking a vagina (50 $\mathrm{mm}$ in diameter and $90 \mathrm{~mm}$ in length) was installed on an acrylic plate $(200 \times 100 \mathrm{~mm})$.

\section{Patient-derived Tumor Phantom}


Next, a tumor phantom representing a typical bulky and irregular-shaped tumor was developed for IC/IS brachytherapy training. The case on which the tumor phantom was modeled was selected through a review of in-house IGABT records. Three-dimensional (3D)-printing techniques were used to create a realscale tumor phantom based on the high-risk clinical target volume (HR-CTV) data. The feasibility of the IC/IS training simulator was investigated by comparing treatment plans derived under various application settings.

A review was made of 495 patients with newly-diagnosed and pathologically-confirmed cervical cancer who were treated with definitive radiotherapy using IGABT at Gunma University Hospital (Maebashi, Gunma, Japan) between 2012 and 2020, and 70 FIGO stage IIIB patients were identified. The details of the definitive radiotherapy are described previously [7]. The pre-treatment MRI obtained at the first brachytherapy session of these 70 FIGO IIIB patients was inspected by three radiation oncologists (KT, $\mathrm{KA}$, and $\mathrm{DI}$ ), and ten patients harboring a bulky tumor with extensive bilateral parametrial involvement were selected. For these ten cases, the HR-CTV was delineated on the T2-weighted MRI according to the recommendations of The Groupe Européen de Curiethérapie and the European Society for Radiotherapy and Oncology $[15,16]$. MIM Maestro software was used for this purpose (version 6.8.7., MIM Software Inc., Cleveland, $\mathrm{OH}, \mathrm{USA}$ ). The HR-CTV contour data were then transferred to OsiriX 64-bit (Pixmeo, Bernex, Switzerland) and subjected to 3D-volume rendering. The three radiation oncologists inspected the 3Dreconstructed HR-CTVs from various angles and identified the best case for use as the phantom for the simulator. The 3D-HR-CTV data of the chosen patient were then transferred to computer-aided design software (Creo Parametric, PTC, Boston, MA, USA) and a 3D-model was printed in acrylonitrile butadiene styrene (ABS) plastic using a 3D printer (Value 3D Magix MF-1100, Mutoh Industries Ltd., Tokyo, Japan). An aluminum mold of the ABS plastic tumor phantom was then created using a CNC (computerized numerical control) milling center (ACCUMILL 4000, DMG Mori Co., Ltd., Nagoya, Aichi). Finally, a semitranslucent soft silicon tumor phantom was created using the mold. Soft silicon was selected as the material for the tumor phantom because it allowed visualization of the needle locations.

\section{Feasibility Test}

The feasibility of the IC/IS training simulator was investigated by comparing six different treatment plans derived by one of two physicians (an expert or a resident) using either a Fletcher-Suit Asian Pacific applicator (sessions \#1-\#3) or a Venezia applicator (sessions \#4-\#6), as outlined in Table 1. In sessions \#1 and \#4, the application of tandem and ovoids was performed by the expert; in sessions \#2 and \#5, the application of tandem, ovoids, and interstitial needles was performed by the resident; and in sessions \#3 and \#6, the application of tandem, ovoids, and interstitial needles was performed by the expert. The expert was a Japanese Society for Radiation Oncology-board certified radiation oncologist who had experience of more than 800 sessions of IC/IS brachytherapy. Four interstitial needles were used and reinsertion was not allowed, although no constraints were set on the insertion locations of the needles. With the Fletcher-Suit Asian Pacific applicator, the interstitial needles were inserted in a freehand manner according to a previous report by our group [10]. 
Table 1

Dose-volume parameters for the treatment plans in feasibility test using Fletcher-Suit Asian Pacific applicator and Venezia applicator

\begin{tabular}{|c|c|c|c|c|c|c|}
\hline $\begin{array}{l}\text { Session } \\
\#\end{array}$ & Type of applicator & Application & Practitioner & $\begin{array}{l}\text { HR-CTV } \\
D_{90}(G y)\end{array}$ & $\begin{array}{l}\text { Rectum } \\
D_{2 c c} \\
\text { (Gy) }\end{array}$ & $\begin{array}{l}\text { Bladde } \\
\mathrm{D}_{2 \mathrm{cc}} \\
(\mathrm{Gy})\end{array}$ \\
\hline 1 & $\begin{array}{l}\text { Fletcher-Suit Asian } \\
\text { Pacific applicator }\end{array}$ & $\mathrm{T} \& \mathrm{O}$ & Expert & 4.23 & 5.99 & 3.73 \\
\hline 2 & $\begin{array}{l}\text { Fletcher-Suit Asian } \\
\text { Pacific applicator }\end{array}$ & $\begin{array}{l}\text { T\&O+ } \\
\text { needles }\end{array}$ & Resident & 5.69 & 5.99 & 4.11 \\
\hline 3 & $\begin{array}{l}\text { Fletcher-Suit Asian } \\
\text { Pacific applicator }\end{array}$ & $\begin{array}{l}\text { T\&O + } \\
\text { needles }\end{array}$ & Expert & 6.70 & 5.98 & 4.05 \\
\hline 4 & Venezia applicator & $\mathrm{T} \& \mathrm{O}$ & Expert & 4.16 & 5.99 & 3.55 \\
\hline 5 & Venezia applicator & $\begin{array}{l}\text { T\&O + } \\
\text { needles }\end{array}$ & Resident & 6.20 & 5.99 & 3.61 \\
\hline 6 & Venezia applicator & $\begin{array}{l}\text { T\&O + } \\
\text { needles }\end{array}$ & Expert & 6.45 & 5.99 & 3.83 \\
\hline
\end{tabular}

At each session, CT images were obtained and the HR-CTV (i.e., the tumor phantom) was delineated using MIM Maestro software following the actual clinical practice used for IGABT. The CT images used to plan the first brachytherapy for the model case were superimposed on those obtained at each test session, and the contours of the rectum and bladder were created on the test session CT images on the basis of the anatomy of the original patient. The contour data were transferred to an Oncentra (Elekta, Stockholm, Sweden) and treatment plans were created based on a high-dose rate ${ }^{192}$ Ir remote-afterloading system (microSelectron, Elekta, Stockholm, Sweden) [7]. The highest possible dose was prescribed to the HR-CTV while keeping the dose constraints for the rectum and bladder set at $D_{2 c c}$ (i.e., the maximum dose at which any $2 \mathrm{cc}$ of the volume is irradiated) below $6 \mathrm{~Gy}$ and $7.6 \mathrm{~Gy}$, respectively [17, 18]. $D_{90}$ (i.e., the minimum dose at which any $90 \%$ of the volume is irradiated) was utilized as the endpoint of dose coverage to the HR-CTV $[17,18]$. For all sessions, the target delineation and dose prescription were performed by the expert.

\section{Results}

The HR-CTV of the model patient at the first brachytherapy session was 68 (left-right) - 49 (anteriorposterior) · 45 (cranial-caudal) $\mathrm{mm}$ in size (Fig. 1a, b, Supplementary Data 1), and the life-size tumor phantom was successfully created using these HR-CTV data (Fig. 1c-f). 
The feasibility test of the IC/IS training simulator using the Fletcher-Suit Asian Pacific applicator without interstitial needles (session \#1) resulted in an unacceptably low HR-CTV $D_{90}$ of $4.23 \mathrm{~Gy}$, clearly demonstrating that the use of a tandem and ovoids alone was inadequate for this tumor, even when positioned by the expert (Table 1, Fig. 3a) $[17,18]$. In session \#2, the resident used four interstitial needles in addition to the tandem and ovoids. Although an evident improvement over session \#1 was observed, the HR-CTV $D_{90}$ was still low at $5.69 \mathrm{~Gy}$ because of insufficient dose coverage in the bilateral and anterior portions of the target (Table 1, Fig. 3b). By contrast, in session \#3, the four needles inserted by the expert were located at peripheral sites in the bilateral and anterior portions of the HR-CTV, which led to greater dose conformity and a satisfactorily high HR-CTV $D_{90}$ of 6.70 Gy (Table 1, Figs. $2 a$ and $3 c$ ). The results of the feasibility test using the Venezia applicator were broadly consistent with those using the Fletcher-Suit Asian Pacific applicator; the HR-CTV $D_{90}$ was 4.16, 6.20, and 6.45 Gy for sessions \#4, \#5, and \#6, respectively (Table 1 , Figs. $2 b$ and $3 d-f$ ).

\section{Discussion}

In this study, we developed a training simulator for IC/IS brachytherapy for locally advanced cervical cancer and evaluated its feasibility with different applicator types and physicians with different levels of experience of IGABT. The patient-derived tumor phantom was shown to be feasible with procedures using Fletcher-Suit Asian Pacific applicator and Venezia applicator with insertion of interstitial needles. Furthermore, the phantom reflected the difference in experience between an expert and a resident, resulting in various HR-CTV $D_{90}$ doses. The results of the present study indicate that the phantom is a good representation of typical bulky and irregular-shaped cervical cancers that are treated with IGABT, and therefore the training simulator appears to be useful for the training of IC/IS brachytherapy for locally advanced cervical cancer.

Despite the efficacy of brachytherapy for cervical cancer, multiple reports indicate that its utilization rate has decreased. In 2013, Han et al. reported a decrease in the brachytherapy utilization rate from $83 \%$ in 1988 to $58 \%$ in 2009, using data from the National Cancer Institute's Surveillance, Epidemiology, and End Results program covering 7359 patients with stage IB2 to IVA cervical cancer who were treated with EBRT. In their study, the use of brachytherapy was independently associated with better cause-specific and overall survival [19]. More recently, Robin et al. reported that according to the National Cancer Database, less than $50 \%$ of cervical cancer patients diagnosed between 2004 and 2012 received a standard of care including EBRT and brachytherapy [20]. Therefore, to increase the utilization rate of brachytherapy, education and training on this modality have become increasingly important. However, the number of brachytherapy procedures performed by residents decreased over the period 2006-2007 to 2010-2011 according to the Accreditation Council of Graduate Medical Education final resident case logs [21]. Moreover, the number of interstitial procedures decreased by $25 \%$ over the period. Thus, education and training on the interstitial procedure can be considered essential for residents. 
Accumulating evidence suggests the efficacy of IC/IS brachytherapy for locally advanced cervical cancers. In a large-scale retrospective study (retroEMBRACE), Fokdal et al. reported that IC/IS brachytherapy resulted in significantly greater HR-CTV $\mathrm{D}_{90}$ compared with intracavitary brachytherapy alone, with no difference in doses to organs at risk [22]. In their study, the 3-year local control rate for patients with an HR-CTV $\geq 30 \mathrm{~cm}^{3}$ was significantly greater when they were treated with IC/IS brachytherapy. More recently, in a multicenter prospective observational study (EMBRACE-I), IC/IS brachytherapy was used in $43.0 \%$ of 1416 cervical cancers, and the overall 5 -year local control was $92 \%$ [6]. In addition, a sub-group analysis of this cohort reported that IC/IS brachytherapy was used for $69.8 \%$ of the cases with bladder wall infiltration [23]. Consistent with these studies, we found that treatment plans with a tandem and ovoids without interstitial needles resulted in an insufficient dose to a bulky HRCTV model (approximately $70 \mathrm{~cm}^{3}$ ), whereas the addition of interstitial needles contributed to a HR-CTV $\mathrm{D}_{90}$ greater than $6 \mathrm{~Gy}$, regardless of applicator type (Table 1). It is worthy to note that an ongoing multicenter prospective interventional study (EMBRACE-II) employs strict dose constraints for the organs at risk, with the planning aim for the total equivalent dose in 2 Gy-fractions with an $\alpha / \beta$ ratio of 3 for $D_{2 c c}$ being set below $65 \mathrm{~Gy}$ and $80 \mathrm{~Gy}$ for the rectum and bladder, respectively [24]. Taken together, these data suggest high demand for the IC/IS technique in the near future. From this standpoint, the training simulator developed in the present study should contribute to the radiation oncology community by supporting education and dissemination of the IC/IS technique.

Optimization of the intratumoral needle location is important for broadening the therapeutic window of IC/IS brachytherapy [25]. Freehand needle application has the advantage of a high degree of freedom in needle position and direction, but the disadvantages of poor reproducibility and difficulty in educating beginners. By contrast, the use of a template for needle application (e.g., Vienna, Utrecht, and Venezia applicator) provides high reproducibility at the cost of reduced degrees of freedom in needle direction [12-14]. To date, no clear indication has been established as to the case types most suited to either the freehand method or templates. In this study, the HR-CTV $D_{90}$ of the plan with freehand needles exceeded that with the Venezia template when the application was performed by the expert (Table 1, Fig. 3). By contrast, the HR-CTV $D_{90}$ of the Venezia-based plan outperformed the freehand-based plan when application was performed by the resident (Table 1, Fig. 3). These findings indicate that the use of a template may be beneficial for residents, whereas freehand needle application by experts may be superior to template-guided needle application in specific clinical situations. Future studies are needed to standardize IC/IS techniques, as well as to establish an educational program for this technique.

The training simulator developed in the present study can be easily replicated from the one-off aluminum mold, which will enable inter-practitioner, -modality, and -institute comparisons of IGABT simulation under standardized settings in the future. We can also use this simulator to examine improvements in the performance of the same practitioner or institute. Furthermore, the 3D-tumor printing pipeline reported in this study is applicable to the production of tumor phantoms tailored to individual patients, which could be used in pre-treatment or post-treatment evaluation of IGABT plans in routine clinical practice. 


\section{Conclusions}

To support IC/IS brachytherapy training for bulky and irregular-shaped cervical cancers, we developed a training simulator consisting of a patient-derived soft silicon tumor phantom and an acrylic tube mimicking the vagina. The results of our feasibility test indicate that the tumor phantom is a good representation of a typical bulky and irregular-shaped cervical cancer to be treated with IGABT, and further evaluation of the training simulator is therefore warranted to confirm its educational value in IC/IS brachytherapy of locally advanced cervical cancer.

\section{List Of Abbreviations}

ABS: acrylonitrile butadiene styrene; $C T$ : computed tomography; $D_{90}$ : the minimum dose at which any $90 \%$ of the volume is irradiated; $D_{2 c c}$ : the maximum dose at which any $2 \mathrm{cc}$ of the volume is irradiated; EBRT: external beam radiotherapy; FIGO: the International Federation of Gynecology and Obstetrics; Gy: Gray [dose unit]; HR-CTV: high-risk clinical target volume; MRI: magnetic resonance imaging; 3D-IGBT: three-dimensional image-guided brachytherapy.

\section{Declarations}

\section{Acknowledgments}

We thank Mr. Nobuyuki Kamei of DIP Co., Ltd. (Ota, Japan) for technical assistance in developing the training simulators. We also thank Dr. Keishiro Mochida and Mr. Yoji Hamano of Gunma University for technical assistance with the feasibility test.

\section{Authors' contributions}

KT: data processing and analysis, development of simulator, writing of the manuscript. T.Oike: conceptualization, development of simulator, manuscript review. KA: clinical recommendations on simulator development. DI: conceptualization and clinical recommendations on simulator development. KM: clinical recommendations on simulator development. MS: data processing and analysis. HS: data processing and analysis. T.Ohno: supervision of project. All authors read and approved the final manuscript.

\section{Funding}

This work was supported by Grants-in-Aid from the Ministry of Education, Culture, Sports, Science, and Technology of Japan for programs for Leading Graduate Schools, Cultivating Global Leaders in Heavy Ion Therapeutics and Engineering, and Gunma University Heavy Ion Medical Center.

\section{Availability of data and materials}

None. 


\section{Ethics approval and consent to participate}

This study was approved by the institutional ethical review committee of Gunma University Hospital (approval number: H2019-226).

\section{Consent for publication}

The requirement for written consent for publication from participants was waived by the institutional ethical review committee of Gunma University Hospital because of the retrospective observational nature of the study.

\section{Competing interests}

This work was supported by MicroSelectron HDR Kenkyukai.

\section{References}

1. Sung H, Ferlay J, Siegel RL, Laversanne M, Soerjomataram I, Jemal A, et al. Global cancer statistics 2020: GLOBOCAN estimates of incidence and mortality worldwide for 36 cancers in 185 countries. CA Cancer J Clin. 2021;71:209-49.

2. Marth C, Landoni F, Mahner S, McCormack M, Gonzalez-Martin A, Colombo N, et al. Cervical cancer: ESMO Clinical Practice Guidelines for diagnosis, treatment and follow-up. Ann Oncol. 2017;28:iv72iv83.

3. Monk BJ, Tewari KS, Koh WJ. Multimodality therapy for locally advanced cervical carcinoma: state of the art and future directions. J Clin Oncol. 2007;25:2952-65.

4. Grover S, Longo J, Einck J, Puri P, Brown D, Chino J, et al. The Unique Issues With Brachytherapy in Low- and Middle-Income Countries. Semin Radiat Oncol. 2017;27:136-42.

5. Marth C, Landoni F, Mahner S, McCormack M, Gonzalez-Martin A, Colombo N, et al. Cervical cancer: ESMO Clinical Practice Guidelines for diagnosis, treatment and follow-up. Ann Oncol. 2017;28(suppl_4):iv72-iv83.

6. Pötter R, Tanderup K, Schmid MP, Jürgenliemk-Schulz I, Haie-Meder C, Fokdal LU, et al. MRI-guided adaptive brachytherapy in locally advanced cervical cancer (EMBRACE-I): a multicentre prospective cohort study. Lancet Oncol. 2021;22(4):538-547.

7. Ohno T, Noda SE, Okonogi N, Murata K, Shibuya K, Kiyohara H, et al. In-room computed tomographybased brachytherapy for uterine cervical cancer: results of a 5-year retrospective study. J Radiat Res. 2017;58:543-51.

8. Pötter R, Dimopoulos J, Georg P, Lang S, Waldhausl C, Wachter-Gerstner N, et al. Clinical impact of MRI assisted dose volume adaptation and dose escalation in brachytherapy of locally advanced cervix cancer. Radiother Oncol. 2007;83:148-55. 
9. Toita T, Kitagawa R, Hamano T, Umayahara K, Hirashima Y, Aoki Y, et al. Phase Il study of concurrent chemoradiotherapy with high-dose-rate intracavitary brachytherapy in patients with locally advanced uterine cervical cancer: efficacy and toxicity of a low cumulative radiation dose schedule. Gynecol Oncol. 2012;126:211-6.

10. Wakatsuki M, Ohno T, Yoshida D, Noda SE, Saitoh J, Shibuya K, et al. Intracavitary combined with CTguided interstitial brachytherapy for locally advanced uterine cervical cancer: introduction of the technique and a case presentation. J Radiat Res. 2011;52:54-8.

11. Okazaki S, Murata K, Noda SE, Kumazaki Y, Hirai R, Mitsunobu I, et al. Dose-volume parameters and local tumor control in cervical cancer treated with central-shielding external-beam radiotherapy and CT-based image-guided brachytherapy. J Radiat Res. 2019;60:490-500.

12. Dimopoulos JC, Kirisits C, Petric P, Georg P, Lang S, Berger D, et al. The Vienna applicator for combined intracavitary and interstitial brachytherapy of cervical cancer: clinical feasibility and preliminary results. Int J Radiat Oncol Biol Phys. 2006;66(1):83-90.

13. Jürgenliemk-Schulz IM, Tersteeg RJ, Roesink JM, Bijmolt S, Nomden CN, Moerland MA, et al. MRIguided treatment-planning optimisation in intracavitary or combined intracavitary/interstitial PDR brachytherapy using tandem ovoid applicators in locally advanced cervical cancer. Radiother Oncol. 2009;93(2):322-30.

14. Walter F, Maihöfer C, Schüttrumpf L, Well J, Burges A, Ertl-Wagner B, et al. Combined intracavitary and interstitial brachytherapy of cervical cancer using the novel hybrid applicator Venezia: Clinical feasibility and initial results. Brachytherapy. 2018;17(5):775-781.

15. Haie-Meder Haie-Meder C, Pötter R, Van Limbergen E, Briot E, De Brabandere M, Dimopoulos J, et al. Recommendations from Gynaecological (GYN) GEC-ESTRO Working Group (I): concepts and terms in 3D image based 3D treatment planning in cervix cancer brachytherapy with emphasis on MRI assessment of GTV and CTV. Radiother Oncol. 2005;74:235-45.

16. Pötter R, Haie-Meder C, Van Limbergen E, Barillot I, De Brabandere M, Dimopoulos J, et al. Recommendations from gynaecological (GYN) GEC ESTRO working group (II): concepts and terms in 3D image-based treatment planning in cervix cancer brachytherapy-3D dose volume parameters and aspects of 3D image-based anatomy, radiation physics, radiobiology. Radiother Oncol. 2006;78:6777.

17. Ohno T, Wakatsuki M, Toita T, Kaneyasu Y, Yoshida K, Kato S, et al. Recommendations for high-risk clinical target volume definition with computed tomography for three-dimensional image-guided brachytherapy in cervical cancer patients. J Radiat Res. 2017;58:341-50.

18. Otani Y, Ohno T, Ando K, Murata K, Kato S, Noda SE, et al. Dosimetric feasibility of computed tomography-based image-guided brachytherapy in locally advanced cervical cancer: a Japanese prospective multi-institutional study. J Radiat Res. 2021;62:502-10.

19. Han K, Milosevic M, Fyles A, Pintilie M, Viswanathan AN, et al. Trends in the utilization of brachytherapy in cervical cancer in the United States. Int J Radiat Oncol Biol Phys. 2013;87(1):1119. 
20. Robin TP, Amini A, Schefter TE, Behbakht K, Fisher CM et al. Disparities in standard of care treatment and associated survival decrement in patients with locally advanced cervical cancer. Gynecol Oncol. 2016;143(2):319-325.

21. Compton JJ, Gaspar LE, Shrieve DC, Wilson LD, Griem KL, Amdur RJ, et al. Resident-reported brachytherapy experience in ACGME-accredited radiation oncology training programs. Brachytherapy. 2013;12(6):622-7.

22. Fokdal L, Sturdza A, Mazeron R, Haie-Meder C, Tan LT, Gillham C, et al. Image guided adaptive brachytherapy with combined intracavitary and interstitial technique improves the therapeutic ratio in locally advanced cervical cancer: Analysis from the retroEMBRACE study. Radiother Oncol. 2016;120(3):434-440.

23. Spampinato S, Fokdal LU, Pötter R, Haie-Meder C, Lindegaard JC, Schmid MP, et al. Risk factors and dose-effects for bladder fistula, bleeding and cystitis after radiotherapy with imaged-guided adaptive brachytherapy for cervical cancer: An EMBRACE analysis. Radiother Oncol. 2021;158:312-320.

24. Pötter R, Tanderup K, Kirisits C, de Leeuw A, Kirchheiner K, Nout R, et al. The EMBRACE II study: The outcome and prospect of two decades of evolution within the GEC-ESTRO GYN working group and the EMBRACE studies. Clin Transl Radiat Oncol. 2018;9:48-60.

25. Oike T, Ohno T, Noda SE, Kiyohara H, Ando K, Shibuya K, et al. Can combined intracavitary/interstitial approach be an alternative to interstitial brachytherapy with the Martinez Universal Perineal Interstitial Template (MUPIT) in computed tomography-guided adaptive brachytherapy for bulky and/or irregularly shaped gynecological tumors? Radiat Oncol. 2014;16;9:222.

\section{Figures}



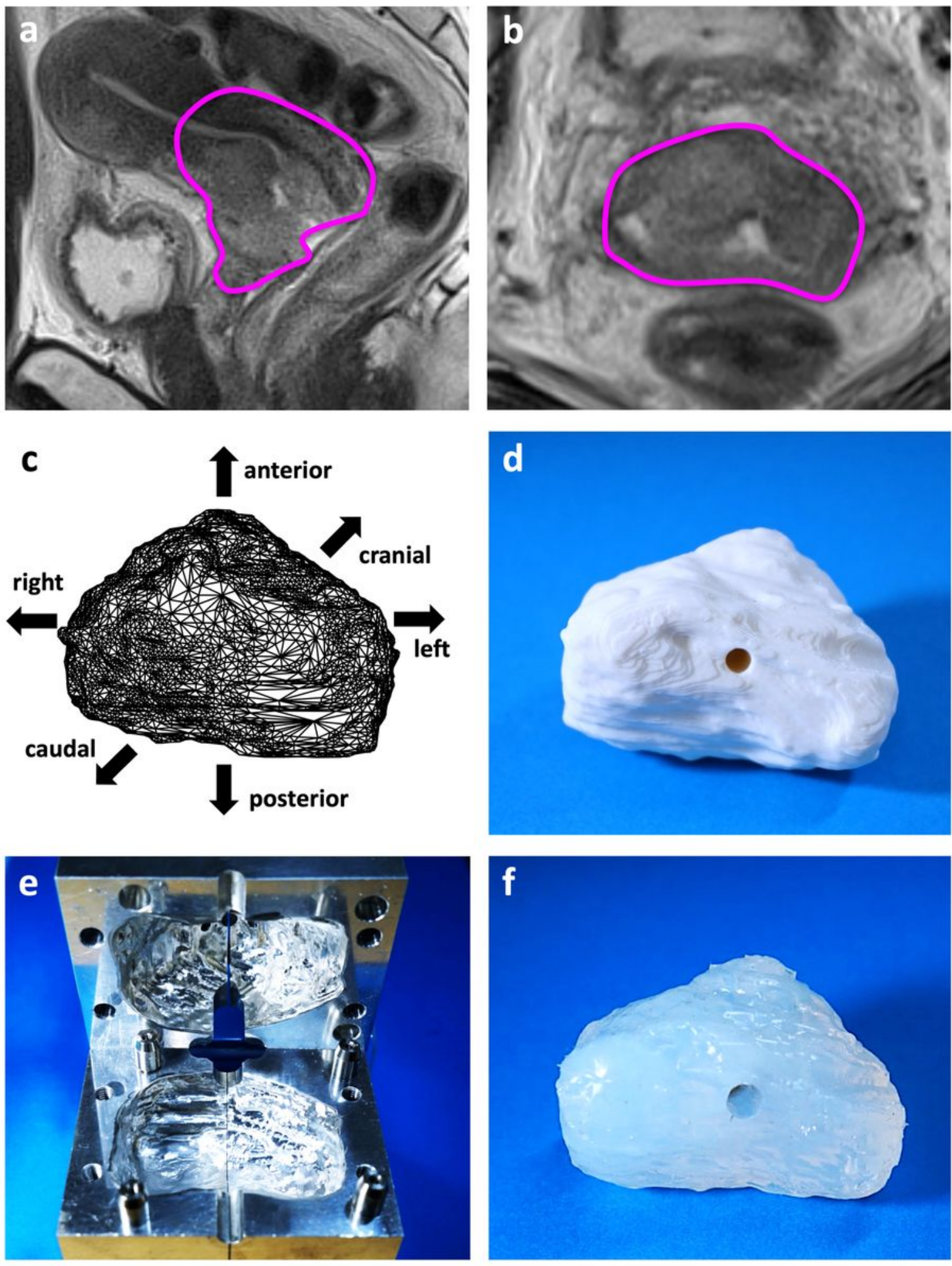

\section{Figure 1}

Production of the patient-derived tumor phantom using three-dimensional (3D) printing. (a) T2-weighted magnetic resonance images of the model patient obtained at the first brachytherapy session. The highrisk clinical target volume is delineated in magenta in the sagittal plane and (b) axial plane. (c) The highrisk clinical target volume (HR-CTV) data in computer-aided design software. (d) HR-CTV model printed in acrylonitrile butadiene styrene (ABS) plastic using a 3D printer. (e) Aluminum mold created against the 
ABS plastic HR-CTV model. (f) Semi-translucent soft silicon HR-CTV model created from the aluminum mold.
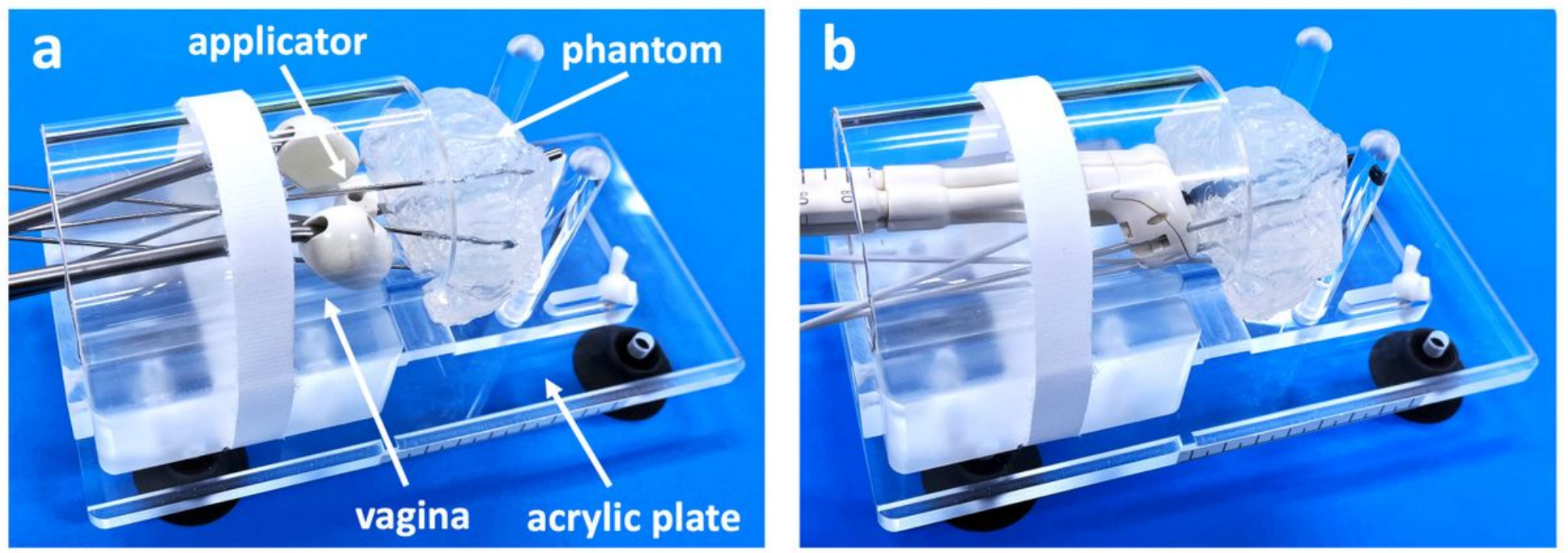

Figure 2

Presentation of the training simulator for intracavitary and interstitial brachytherapy.

(a) With Fletcher-Suit Asian Pacific applicator and interstitial needles. (b) With Venezia applicator and interstitial needles. 

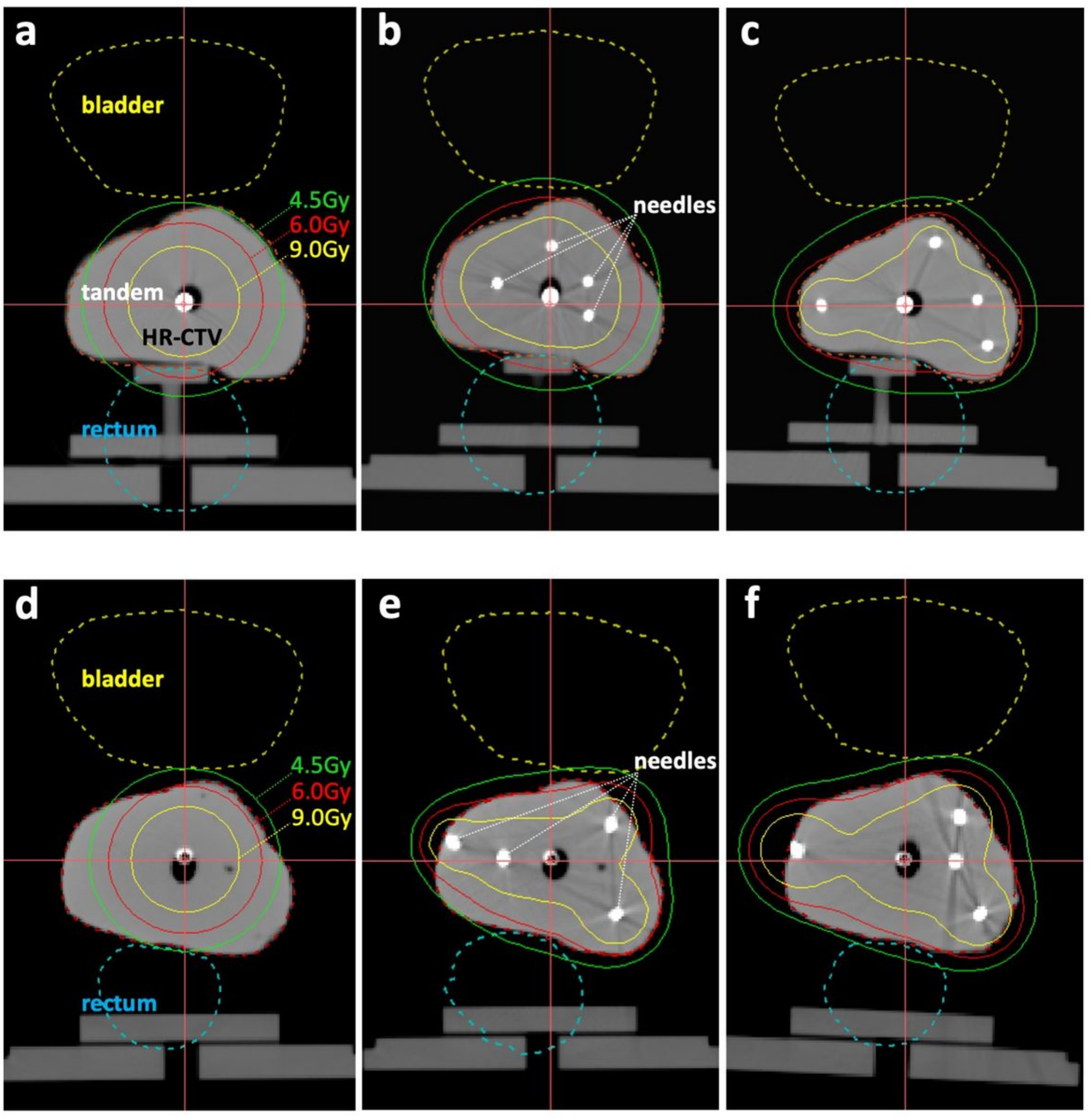

\section{Figure 3}

Representative dose-distributions for the treatment plans in the feasibility tests using a Fletcher-Suit Asian Pacific applicator or Venezia applicator. (a) Session \#1 (expert using Fletcher-Suit Asian Pacific applicator without interstitial needles), (b) Session \#2 (resident using Fletcher-Suit Asian Pacific applicator with interstitial needles), (c) Session \#3 (expert using Fletcher-Suit Asian Pacific applicator with interstitial needles), (d) Session \#4 (expert using Venezia applicator without interstitial needles), (e) 
Session \#5 (resident using Venezia applicator with interstitial needles), and (f) Session \#6 (expert using Venezia applicator with interstitial needles).

\section{Supplementary Files}

This is a list of supplementary files associated with this preprint. Click to download.

- SupplementaryData1.stl 